\title{
Comparison of Intravenous and Intra-Articular Use of Tranexamic Acid on Blood Loss after Primary Total Knee Arthroplasty
}

\author{
Jagseer Singh $^{1}$, Harpreet Kaur $^{2 *}$
}

${ }^{1}$ Associate Professor, Department of Orthopaedics, Adesh Institute of Medical Sciences and Research, Bathinda, Punjab, India

${ }^{2}$ Professor, Department of Physiology, Adesh Institute of Medical Sciences and Research, Bathinda, Punjab, India

DOI: $10.36347 /$ sjams.2020.v08i08.035

| Received: 07.08.2020 | Accepted: 21.08.2020 | Published: 30.08 .2020

*Corresponding author: Dr. Harpreet Kaur

Abstract

Original Research Article

Total Knee Arthroplasty is associated with significant amount of blood loss and may increase the need of blood transfusions. Various blood loss management strategies have been used in the past and Tranexamic Acid is one such commonly used method due to ease of administration and low cost. The use of TXA in primary TKA is associated with reduced transfusion rates, early discharge to home, and reduced economic burden on the patient. Tranexamic Acid can be administered through various routes that include oral, intravenous and intra-articular. However there is no clear consensus on the ideal dosage and route of administration. This study was conducted to compare the effect of intra-venous Tranexamic acid with intra-articular Tranexamic acid on post-operative blood loss after unilateral primary total knee arthroplasty (TKA).A total of 58 patients of either gender planned to undergo unilateral total knee replacement (TKR) were enrolled in each of the two groups. In group A (Intra venous Tranexamic acid group) 2 gram intra venous Tranexamic acid was injected. In Group B (Intra-articular Tranexamic acid group), patients were given 2 gram intra-articular Tranexamic acid. All patients were followed up to 72 hours after completion of surgery. Blood collection in negative suction drain was noted after every 24 hours. The mean drainage total blood loss during 72 hours was $637.32 \pm 103.53 \mathrm{ml}$ in Group A (intravenous Tranexamic acid)) and $546.35 \pm 70.73 \mathrm{ml}$ in Group B (Intraarticular Tranexamic acid). The difference was significant in Group A and Group B.Patients who received intraarticular TXA had a lesser drain output $(p<0.05)$ as compared to intravenous administration of Tranexamic Acid. Intra-articular administration of TXA is more effective in reducing postoperative blood loss after primary TKA as compared to intravenous route.

Keywords: Blood loss, Intravenous, Intra-articular, Total knee arthroplasty, Tranexamic acid.

Copyright @ 2020: This is an open-access article distributed under the terms of the Creative Commons Attribution license which permits unrestricted use, distribution, and reproduction in any medium for non-commercial use (NonCommercial, or CC-BY-NC) provided the original author and source are credited.

\section{INTRODUCTION}

Although Total Knee Arthroplasty (TKA) is one of the most successful surgeries done to relieve pain of severe Osteoarthritis Knee, but the blood loss during the surgery and post-operatively is estimated to be $800 \mathrm{~mL}-1200 \mathrm{~mL}$ and therefore remains a major issue [1]. TKA is one of the most common reasons for allogenic blood transfusion in patients undergoing surgery [2]. Allogenic blood transfusions are associated with many risks that include hemolytic reaction, fluid and hemodynamic overload, acute lung injury, coagulopathy, allergic reaction, febrile non-hemolytic reaction and risks of disease transmission [3]. Therefore blood management strategies aim at reducing the need for allogenic blood transfusions but preventing the anaemia as well.

Tranexamic acid (TXA) is an antifibrinolytic agent that promotes the formation of stable hemostasis and is effective in reducing blood loss during total knee arthroplasty (TKA) [4]. TXA inhibits the activation of plasminogen to plasmin by blocking the lysine binding sites of plasminogen to fibrin. The result is decreased proteolytic action on fibrin monomers and fibrinogen, leading to clot stabilization [5]. The use of TXA in primary TKA is associated with reduced transfusion rates, reduced duration of hospital stay and decreased economic burden on the patient [6]. While TXA have been reported to be used by oral, intra-articular and intravenous routes in total knee arthroplasty (TKA), there is no clear consensus on the optimal route of administration $[7,8]$.

\section{ОвJJECTIVE}

The objective of the study was to compare the effect of intra-venous Tranexamic acid with intraarticular Tranexamic Acid on drainage blood loss after unilateral primary total knee arthroplasty (TKA). 


\section{Material ANd Methods}

In this study a total of 56 patients of severe osteoarthritis of knee enrolled for unilateral primary total knee arthroplasy(TKA) admitted in Orthopaedics Department of Adesh Institute of Medical Sciences and Research (AIMSR), Bathinda, Punjab from January 2020 to July 2020 who fulfill the inclusion criteria are included. All the patients were operated by the same surgical team. Informed consent from patients was taken. Approval from Institutional Ethical Committee was taken. Selected patients were divided into two groups. Patients in which intravenous Tranexamic acid was given, were allotted Group A. Group B consisted of the patients in which intra-articular Tranexamic acid was given.

\section{Inclusion Criteria}

Patients of age 45-71 years of either gender presenting with Osteoarthritis knee and planned to undergo unilateral primary TKA.

\section{Exclusion Criteria}

Patients with major deformities that would lead to extensive bone cuts or release of a more extensive area of soft tissue, patients who had undergone previous surgeries of the same knee, INR $>2$, haemoglobin $<10 \mathrm{gm} / \mathrm{dL}$, taking atorvastatins or aspirin, cardiac disease, IV drug abuser, alcoholics, thalassemia or leukemia, thrombocytopenia, idiopathic thrombocytopenic purpura, deep vein thrombosis were excluded.

\section{Procedure}

All surgeries are done under spinal anaesthesia by single surgical team through midline vertical skin incision. Arthrotomy was done through medial parapatellar approach. Tourniquet was inflated at pressure of $350 \mathrm{mmHg}$ before giving skin incision. Trial implant was put after making appropriate bone cuts and soft tissue releases. Cemented prosthesis was implanted after washing the bone surfaces with Pulse lavage. In Group A (I.v. Tranexamic group) 1 gram Tranexamic acid was given through intra venous route 15 minutes before tourniquet release. Second dose of 1 gram Tranexamic acid was given 3 hours after surgery.
Wound was stitched in layers over negative suction drain. $50 \mathrm{ml}$ of normal saline was injected intraarticularly before doing dressing. In Group B, 2 gram Tranexamic acid diluted in $50 \mathrm{ml}$ normal saline was injected intra-articularly. Tourniquet was released after closure of wound. Drain was clamped for 15 minutes for absorption of Tranexamic acid. Patient was shifted to post surgical care facility. Patients were followed up for next 72 hours. Blood loss (collected in negative suction drain) was noted after every 24 hours for next 72 hours.

\section{Data Analysis}

Data was analysed using OpenEpi software. By taking $p$-value $\leq 0.05$ as statistically significant, for comparing mean of these various variables, independent sample test $t$-test was applied. Mean and standard deviations were calculated for age and blood loss.

\section{RESULTS}

Mean age of patients In Group A (i.v Tranexamic Acid) was 57.78 \pm 6.74 ,years, in Group B (Intra articular Tranexamic acid) was $58.75 \pm 6.97$ years. Male to female ratio in Group A was 10:18 and in Group B was11:17. There were 4(14\%) hypertensive patients in group A and 5(18\%) in Group B and 2(7\%) diabetic patients in Group A and 3(11\%) in Group B. (Table 1)

The mean blood loss during first 24 hours was $270.25 \pm 41.76 \mathrm{ml}$ in Group A and $220.17 \pm 37.86 \mathrm{ml}$ in Group B. The difference was statistically significant $(\mathrm{p}=0.0000182)$. The mean blood loss during next 24 hours was $214.39 \pm 42.56 \mathrm{ml}$ in Group $\mathrm{A}$ and $192.10 \pm 24.06 \mathrm{ml}$ in Group B. The difference was significant $(\mathrm{p}=0.0192)$. The mean blood loss during next 24 hours was $152.67 \pm 29.43 \mathrm{ml}$ in Group $\mathrm{A}$ and $134.10 \pm 26.67 \mathrm{ml}$ in Group B. The difference was significant in Group A and Group B $(\mathrm{p}=0.0165)$. The mean drainage total blood loss during 72 hours was $637.32 \pm 103.53 \mathrm{ml}$ in Group A (intravenous Tranexamic acid)) and $546.35 \pm 70.73 \mathrm{ml}$ in Group B (Intra-articular Tranexamic acid). The difference was significant in Group A and Group B ( $\mathrm{p}=0.000326)$. (Table 2)

Table-1: Demography of patients in two groups

\begin{tabular}{|c|c|c|}
\hline & I.v. Tranexamic acid group & Intra-articular Tranexamic acid group \\
\hline Number & 28 & 28 \\
\hline Age (years) & $57.78 \pm 6.74$ & $58.75 \pm 6.97$ \\
\hline Male & 10 & 11 \\
\hline Female & 18 & 17 \\
\hline Hypertension & $4(14 \%)$ & $5(18 \%)$ \\
\hline Diabetes & $2(7 \%)$ & $3(11 \%)$ \\
\hline
\end{tabular}


Table-2: Comparison of blood loss between two groups (ml)

\begin{tabular}{|c|c|c|c|}
\hline & $\begin{array}{l}\text { I.v. Tranexamic acid } \\
\text { group }\end{array}$ & $\begin{array}{l}\text { Intra-articular Tranexamic } \\
\text { acid group }\end{array}$ & p-value \\
\hline N & 28 & 28 & \\
\hline First 24 hour & $270.25 \pm 41.76$ & $220.17 \pm 37.86$ & $=0.0000182$ \\
\hline Second 24hour & $214.39 \pm 42.56$ & $192.10 \pm 24.06$ & $=0.0192$ \\
\hline Third 24 hours & $152.67 \pm 29.43$ & $134.10 \pm 26.67$ & $=0.0165$ \\
\hline $\begin{array}{l}\text { Total blood loss(after } \\
72 \text { hours) }\end{array}$ & $637.32 \pm 103.53$ & $546.35 \pm 70.73$ & $=0.000326$ \\
\hline
\end{tabular}

\section{DiscUSSION}

Different measures are used to reduce intra operative blood loss have been employed in orthopedic surgery to reduce the need for transfusion and hasten the patient's recovery in the post-operative period [9]. One technique is transfusion of autologous blood which also reduces the risk of infection and risk of transfusion reaction but it is expensive and not every center has facility for this $[9,10]$. Another technique to reduce perioperative blood loss is the application of antifibrinolytic agents including aprotinin, epsilonaminocaproic acid, and tranexamic acid (TXA). Among them, Tranexamic acid is used most commonly. It can be given intravenous or intra-articular during the surgery [11].

In our study, we concluded that intra-articular administration of 2 gram Tranexamic Acid is more effective in reducing drainage blood loss after unilateral primary TKA as compared to intra venous route. The difference in post operative blood loss between Group A(intra venous Tranexamic acid) and group B( Intra articular Tranexamic acid) is statistically significant $(\mathrm{p}=0.000326)$. Similar results have been reported by various other studies.

Yuhui Wang et al. concluded that intraarticular injection of tranexamic acid has significant hemostatic effect for TKA surgery and it can effectively reduce the occult blood loss, postoperative drainage volume as well as total blood loss and prevent the incidence of deep venous thrombosis and improve the prognosis in patients of practical application value [12].

The study by Seo JG et al. showed that as compared to intravenous administration, intra-articular administration of Tranexamic Acid seems to be more effective in terms of reducing blood loss and transfusion frequency. Tranexamic Acid may improve the general conditions of patients given TKA by maintaining a hemodynamically stable state, aiding in recovery, and reducing the chance of transfusion-associated side effects and complications [13].

Prakash $\mathrm{J}$ et al. showed that intra-articular administration through drain and IV administration are equally effective and superior to topical wash method in reducing blood loss, haemoglobin fall and transfusion requirements [14].
The meta-analysis conducted by Shin YS et al indicates that IV administration of $10 \mathrm{mg} / \mathrm{kg}$ of TXA 20 min before inflation of the tourniquet followed by 10 $\mathrm{mg} / \mathrm{kg}$ of TXA $15 \mathrm{~min}$ before deflation of the tourniquet is effective and safe. The topical administration of $2 \mathrm{~g}$ of TXA mixed with $100 \mathrm{~mL}$ of normal saline after wound closure could be an alternative option in patients at greater risk of thromboembolic complications [15].

The biggest limitation of this study is that it is an observational study and there may have been a bias during selection of the patients. Secondly, the intraoperatrive blood loss was not evaluated. Thirdly, the effects of intra-venous and intra-articular tranexamic acid on coagulation profile should also have been compared as it can be expected that intra-articular tranexamic acid may not be having as much systemic deleterious effects as expected from intravenous administration.

\section{Conclusion}

Tranexamic acid effectively reduces the postoperative drainage blood loss given through both the intra-articular or intravenous route. However there is less post-operative blood loss in patients who received tranexamic Acid through the intra-articular route. Due to convenience of use, the intra-articular route of administration of tranexamic acid after primary TKA may be considered for future practice.

\section{REFERENCES}

1. Reinhardt KR, Osoria H, Nam D, Alexiades MA, Figgie MP, Su EP.Reducing blood loss after total knee replacement: a fibrin solution. Bone Joint J. 2013; 95(11), 135-139.

2. Shortt J, Polizzotto MN, Waters N, Borosak M, Moran M, Comande M, Devine A, Jolley DJ, Wood EM. Assessment of the urgency and deferability of transfusion to inform emergency blood planning and triage: the Bloodhound prospective audit of red blood cell use. Transfusion. 2009; 49:2296303.

3. Goodnough LT, Shuck JM. Risks, options, and informed consent for blood transfusion in elective surgery. Am J Surg. 1990;159:602-9.

4. Wang HY, Kang PD, Pei FX. [A study on the effectiveness and safety of tranexamic acid to reduce blood loss during the perioperative period of 
total hip arthroplasty.] Chinese Journal of Bone and Joint. 2015; 8: 649-54.

5. Dunn CJ, Goa KL. Tranexamic acid: a review of its use in surgery and other indications. Drugs. 1999;57:1005-32

6. Tuttle JR, Ritterman SA, Cassidy DB, Anazonwu WA, Froehlich JA, Rubin LE. Cost benefit analysis of topical tranexamic acid in primary total hip and knee arthroplasty. J Arthroplasty. 2014; 29:1512-5.

7. Soni A, Saini R, Gulati A, Paul R, Bhatty S, Rajoli SR. Comparison between intravenous and intraarticular regimens of tranexamic acid in reducing blood loss during total knee arthroplasty. J Arthroplasty. 2014;29(8):1525-7.

8. Hamlin BR, DiGioia AM, Plakseychuk AY, Levison TJ. Topical versus intravenous tranexamic acid in total knee arthroplasty. J Arthroplasty. 2015;30(3):384-6.

9. Park JH, Choi SW, Shin EH, Park MH, Kim MK. The optimal protocol to reduce blood loss and blood transfusion after unilateral total knee replacement: Low-dose IA-TXA plus 30-min drain clamping versus drainage clamping for the first $3 \mathrm{~h}$ without IA-TXA. J Orthop Surg (Hong Kong). 2017;25(3):2309499017731626.

10. Sahu S, Hemlata VermaA. Adverse events related to blood transfusion. Indian J Anaesth. 2014;58(5), 543-551.
11. Danninger T, Memtsoudis SG. Tranexamic acid and orthopedic surgery-the search for the holy grail of blood conservation. Ann Transl Med. 2015;3(6):77.

12. Yuhui Wang, Yue She, Wuyin Li. Comparison of the effect of intravenous and intra-articular injection of tranexamic acid on blood loss in total knee arthroplasty. Pharm. Bioprocess. 2018; 6(3), 089-092.

13. Seo JG, Moon YW, Park SH, Kim SM, Ko KR. The comparative efficacies of intra-articular and IV tranexamic acid for reducing blood loss during total knee arthroplasty [published correction appears in Knee Surg Sports Traumatol Arthrosc. 2013 Aug; 21(8):1875. Knee Surg Sports Traumatol Arthrosc. 2013;21(8):1869-1874.

14. Prakash J, Seon JK, Park YJ, Jin C, Song EK. A randomized control trial to evaluate the effectiveness of intravenous, intra-articular and topical wash regimes of tranexamic acid in primary total knee arthroplasty. J Orthop Surg (Hong Kong). 2017;25(1):2309499017693529.

15. Shin YS, Yoon JR, Lee HN, Park SH, Lee DH. Intravenous versus topical tranexamic acid administration in primary total knee arthroplasty: a meta-analysis. Knee Surg Sports Traumatol Arthrosc. 2017;25(11):3585-3595. 